Gut, 1980, 21, 1090-1092

Epidemiology

\title{
Gallstones and the risk of cancer
}

\author{
A B LOWENFELS
}

From the Department of Surgery, New York Medical College, New York, USA

SUMMARY For both males and females the age-standardised prevalence of asymptomatic gallstones found at necropsy in 15 countries correlated strongly with age-standardised mortality from cancers of the uterus, large bowel, and stomach. When deaths from cholecystitis were used as another measure of the frequency of gallstones similar positive correlations were observed across 28 countries. The results suggest that cholelithiasis and several common cancers share similar epidemiological and perhaps metabolic factors.

In addition to the well-known association between cholelithiasis and biliary tract malignancy it has been suggested that gallstones may be linked through diet with colorectal cancer. ${ }^{1}$ However, efforts to correlate these two diseases in individual population groups have yielded conflicting results, ${ }^{2-5}$ perhaps because of methodological problems in choosing appropriate controls.

As gallstones are largely made up of cholesterol, any link between gallstones and bowel cancer might lend additional support to the cholesterol/bile acid hypothesis for the aetiology of bowel cancer. Furthermore, it seems reasonable that the presence or absence of gallstones might prove to be a more reliable indication of cholesterol 'burden' than blood cholesterol, which is difficult to associate with diet and which has not been positively correlated with colon cancer. ${ }^{6}$

To clarify the problem of gallstones and cancer, the prevalence of gallstones in various countries has been estimated and correlated with available data on cancer mortality.

\section{Methods}

The prevalence of gallstones in healthy, asymptomatic individuals has been determined in only a few countries and therefore the reported frequency of asymptomatic gallstones discovered at necropsy was used as a substitute. From a review of available published studies since 1950, 15 countries were

*Address for correspondence: Department of Surgery, Munger Pavilion, New York Medical College, Valhalla, New York, USA 10595.

Received for publication 5 August 1980 selected where there were sufficient age-specific data to calculate age-standardised rates for males and females above the age of 20 years. ${ }^{7-21}$ Prevalence rates were age-standardised by decade to a world population.

In addition, as death from biliary tract disease is nearly always related to gallstones, it seemed reasonable to use available mortality data for cholecystitis as another measure of the frequency of gallstones in different countries. Age-specific cholecystitis mortality rates by decade for 1978 and 1979 were collected from World Health Organization reports and used to calculate age-standardised rates for 28 countries where there were 100 or more deaths from cholecystitis. ${ }^{22}$ Age-standardised deaths from cholecystitis were related to the age-adjusted prevalence of gallstones at necropsy for both males $(r=0.76$; $\mathrm{P}=<0.01)$ and females $(r=0.82 ; \mathrm{P}=<0.01)$.

Table 1 Age-adjusted prevalence of asymptomatic gallstones at necropsy in 15 countries

\begin{tabular}{llc}
\hline Country & \multicolumn{2}{l}{ Gallstone prevalence (\%) } \\
\cline { 2 - 3 } & Females & Males \\
\hline Chile $^{7}$ & $42 \cdot 0$ & $16 \cdot 7$ \\
Czechoslovakia $^{8}$ & $23 \cdot 3$ & $13 \cdot 2$ \\
Sweden $^{9}$ & $22 \cdot 4$ & $9 \cdot 1$ \\
Scotland $^{10}$ & $21 \cdot 7$ & $9 \cdot 9$ \\
England $^{11}$ & $20 \cdot 5$ & $12 \cdot 2$ \\
W Germany $^{12}$ & $20 \cdot 0$ & $7 \cdot 2$ \\
New Zealand $^{13}$ & $14 \cdot 2$ & $9 \cdot 0$ \\
United States $^{14}$ & $14 \cdot 1$ & $5 \cdot 2$ \\
Australia $^{15}$ & $13 \cdot 9$ & $6 \cdot 0$ \\
Japan $^{16}$ & $13 \cdot 0$ & $5 \cdot 3$ \\
Ireland $^{17}$ & $12 \cdot 4$ & $3 \cdot 4$ \\
Norway $^{18}$ & $10 \cdot 4$ & $5 \cdot 3$ \\
Greece $^{10}$ & $6 \cdot 8$ & $3 \cdot 5$ \\
Singapore & & $4 \cdot 3$ \\
Thailand $^{21}$ & $6 \cdot 6$ & $2 \cdot 3$ \\
\hline
\end{tabular}


Table 2 Age-adjusted gallstone prevalence at necropsy, 1952-79, and age-adjusted mortality from cancer, $1974-75$, in 15 countries*

\begin{tabular}{lll}
\hline & \multicolumn{2}{l}{ Simple correlation coefficients } \\
\cline { 2 - 3 } Tumour location & Females & Males \\
\hline Uterus & $0.93 \dagger$ & - \\
Colorectal & $0.73 \ddagger$ & $0.63 \S$ \\
Stomach & 0.51 & 0.45 \\
Stomach (excluding Japan) & $0.75 \ddagger$ & $0.71 \ddagger$ \\
All sites & $0.60 \S$ & $0.52^{* *}$ \\
Lung & 0.02 & 0.31 \\
Prostate & - & 0.33 \\
Breast & 0.23 & - \\
Skin & 0.02 & 0.05 \\
\hline
\end{tabular}

*Same countries as shown in table 1.

$+\mathrm{P}=<0.001 ; \neq \mathrm{P}=<0.01 ; \S \mathrm{P}=<0.02 ; * * \mathrm{P}=0.05$.

Both of these measures of the frequency of gallstones in various countries were then correlated with age-standardised mortality rates for common human cancers $^{23}$ and simple correlation coefficients $(r)$ were calculated. Singapore was excluded from the analysis of uterine cancer because the total number of deaths for that site was less than 100 .

\section{Results}

The age-standardised prevalence of asymptomatic gallstones discovered at necropsy (Table 1) varied markedly from country to country and, as expected, gallstones were approximately twice as common in females as in males. Significant positive correlations were found between the necropsy prevalence of gallstones and colorectal cancers, as well as all cancers in both males and females (Table 2). The correlation between gastric cancer and the necropsy prevalance of gallstones, which was nearly significant
Table 3 Age-adjusted mortality from cholecystitis, 1978-79, and age-adjusted mortality from cancer, 1974-75, in 28 countries*

\begin{tabular}{lcl}
\hline & \multicolumn{2}{c}{ Simple correlation coefficients } \\
\cline { 2 - 3 } Tumour location & Females & Males \\
\hline Uterus & $0.68 \dagger$ & - \\
Colorectal & 0.55 & $0.51 \ddagger$ \\
Stomach & $0.64 \dagger$ & $0.64 \dagger$ \\
All sites & $0.46 \ddagger$ & $0.40^{* *}$ \\
Lung & -0.22 & 0.07 \\
Prostate & - & 0.26 \\
Breast & 0.01 & - \\
Skin & -0.02 & 0.04 \\
\hline
\end{tabular}

*USA, Australia, Austria, Belgium, Bulgaria, Canada, Chile, Czechoslovakia, Denmark, England and Wales, Finland, France, W Germany, Greece, Hungary, Japan, Netherlands, Norway, Philippines, Poland, Roumania, Scotland, Spain, Sweden, Switzerland, Thailand, Uruguay, Yugoslavia.

$\dagger \mathrm{P}=<0.001 ; \ddagger \mathrm{P}=<0.01 ; \S \mathrm{P}=<0.02 ;{ }^{* *} \mathrm{P}=<0.05$.

in the 15 countries studied, became significant in the remaining 14 countries (females: $r=0 \cdot 75, \mathrm{P}=<0.01$; males: $r=0.71, \mathrm{P}=<0.01$ ) when Japan, the obvious out-lier was removed. In females, the strongest correlation $(r=0.93 ; \mathrm{P}=<0.001)$ was discovered between uterine cancer and gallstones (Figure). A strong correlation persisted $(r=0.82 ; \mathrm{P}=<0.001)$ even after exclusion of Chile, a country with excessive rates for cholelithiasis and uterine cancer.

Similar positive correlations were observed between age-standardised mortality from cholecystitis and age-standardised cancer mortality in the 28 countries studied (Table 3).

\section{Discussion}

The ideal method of measuring gallstone frequency would be to use radiographic surveys in asympto-

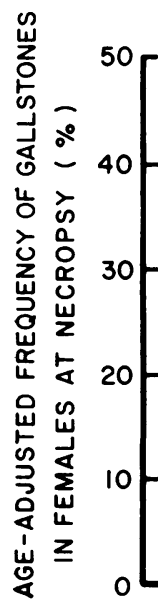

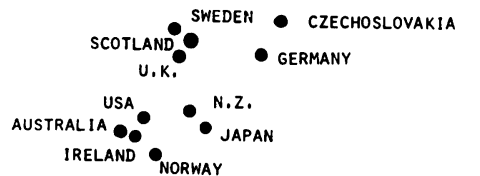

- GREECE

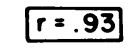

Figure Scattergram showing relationship between ageadjusted mortality rate from uterine cancer/100 000 and ageadjusted frequency of asymptomatic gallstones in females at necropsy in 14 countries. 
matic individuals. Such information is not available and therefore the two methods used represent a compromise. Clearly the prevalence of gallstones in a necropsy population may differ from the population at large, and deaths from cholecystitis, although usually caused by cholelithiasis, may be influenced by confounding variables such as the availability of medical care. Nevertheless, despite these drawbacks, there were similar correlations between both methods used to estimate gallstone frequency and cancer mortality data.

The correlation between cholelithiasis and uterine cancer was exceptionally strong and is consistent with a previous report of an increased frequency of gallstones in women with endometrial cancer. ${ }^{24}$

The association between gallstones and colorectal cancer was also strong. As increased cholesterol excretion may be implicated as a causative factor in cholelithiasis ${ }^{25}$ and as cholesterol is the major source for bile acids, this study strengthens the cholesterol/bile acid hypothesis for the aetiology of colorectal cancer.

There is no ready explanation for the unexpected correlation between gallstones and gastric cancer. It is of interest that this finding is consistent with the observation that Pima Indians of the Southwest United States, who are known to have a great excess of gallstones, also have a higher than expected incidence of gastric cancer. ${ }^{26}$

The findings reported here, although not implying a causal relationship, are consistent with the hypothesis that gallstones and several common human cancers share common risk factors. Additional studies of the incidence of cancer in carefully selected patients with and without gallstones are planned.

I thank Dr M Monk, Dr W Rosenthal, and Dr C Muir for their helpful advice.

\section{References}

${ }^{1}$ Burkitt DP, Tunstall M. Gallstones: Geographical and chronological features. J Trop Med Hyg 1975; 78: 140-4.

${ }^{2}$ Capron JP, Delamarre J, Canarelli JP, Brousse N, Dupas JL. Does cholecystectomy predispose to the development of colorectal cancer? Gastroenterol. Clin Biol 1978; 2 : 383-9.

${ }^{3}$ Choluj B, Ceklovsky J, Nozicka Z. Cholecystectomy and carcinoma of the large intestine. Cesk Gastroenterol $V y z$ 1979; 33: 13-25.

${ }^{4}$ Hoare AM, Carcinoma of the colon and cholecystectomy. Lancet $1974 ; 2$ : 1395-96.

${ }^{5}$ Castleden WM, Doouss TW, Jennings KP, Leighton M. Gallstones, carcinoma of the colon and diverticular disease. Clin Oncol 1978; 4: 139-44.
${ }^{6}$ Rose G, Blackburn H, Keys A, Taylor HL, Kannel WB, Paul O, Reid DD, Stamler J. Colon cancer and blood cholesterol. Lancet 1974; 1: 181-3.

${ }^{7}$ Marinovic I, Guerra C, Larach G. Incidence of cholelithiasis in autopsy material and analysis of the composition of calculi. Rev Med Chile 1972; 100: 1320-27.

${ }^{8}$ Zahor Z, Sternby NH, Kagan A, Uemura K, Vanecek R, Vichert AM. Frequency of choelithiasis in Prague and Malmo. An autopsy study. Scand J Gastroenterol 1974; 9: 3-7.

${ }^{9}$ Lindstrom CG. Fequency of gallstone disease in a welldefined Swedish population. Scand J Gastroenterol 1977; 12: 341-6.

${ }^{10}$ Bateson MC, Bouchier IAD. Prevalence of gallstones in Dundee: a necropsy study. $\mathrm{Br}$ Med J 1975; 4: 427-30.

${ }^{11}$ Barker DJP, Gardner MJ, Power C, Hutt MSR. Prevalence of gallstones at necropsy in nine British towns: a collaborative study. Br Med J 1979; 2: 138992.

${ }^{12}$ Rodewald H. Pathology of the gallbladder. II. Frequency of gallstones. Zbl Allg Pathol 1957; 96: 300-2.

${ }^{13}$ Doouss TW, Castleden WM. Gallstones and carcinoma of the large bowel NZ Med J 1973; 77:162-5.

${ }^{14}$ Lieber MM. The incidence of gallstones and their correlation with other diseases. Ann Surg 1952; 135: 394-405.

${ }^{15}$ Cleland JB. Gallstones in 7,000 postmortem examinations. Med J Aust 1953; 40: 488-9.

${ }^{16}$ Newman HF, Northrup JD. The autopsy incidence of gallstones. Int Abstr Surg 1959; 109: 1-13.

${ }^{17}$ Hogan J, Lonergan M, Holland PD. The incidence of cholelithiasis in an autopsy series. Ir Med J 1977; 70: 608-11.

${ }^{18}$ Torvik A, Hoivik B. Gallstones in an autopsy series. Incidence, complications and correlations with carcinoma of the gallbladder. Acta Chir Scand 1960; 120: 168-74.

${ }^{19}$ Kalos A, Delidou A, Kordosis T, Archimandritis A, Gaganis A, Angelopoulos B. The incidence of gallstones in Greece; an autopsy study. Acta Hepatogastroenterol 1977; 24: 20-3.

${ }^{20} \mathrm{Hwang}$ WS. Cholelithiasis in Singapore. Part I: A necropsy study. Gut 1970; 11 : 141-52.

${ }^{21}$ Stitnimankarn $\mathrm{T}$. The necropsy incidence of gallstones in Thailand. Amer J Med Sci 1960; 240: 349-52.

${ }^{22}$ WHO. World health statistics annual 1978, 1979. Geneva: WHO, 1979-80.

${ }^{23}$ American Cancer Society, Cancer facts and figures, 1980. New York: American Cancer Society, 1979: 14.

${ }^{24}$ Mack TM, Pike MC, Henderson BE, Pfeffer RI, Gerkins VR, Arthur M, Brown SE. Estrogens and endometrial cancer in a retirement community. $N$ Engl $J$ Med 1976; 294: 1262-7.

${ }^{25}$ Valdivieso V, Palma R, Nervi F, Covarrubias C, Severin C. Secretion of biliary lipids in young Chilean women with cholesterol gallstones. Gut 1979; 20: 997-1000.

${ }^{26}$ Sievers ML. Unusual comparative frequency of gastric carcinoma, pernicious anemia, and peptic ulcer in Southwestern American Indians. Gastroenterology $1973 ; 65: 867-76$. 